\title{
Content of Blue Book 2011
}

Glenn Everett

Office for National Statistics

\section{Summary}

The Quarterly National Accounts consistent with Blue Book 2011 (BB11) and Pink Book 2011 (PB11) will be published on 5 October 2011. Electronic publication of the BB11 and PB11 will be on 1 November 2011. In line with ONS policy, this article informs users about the content of these publications, including changes from previous years.

\section{Introduction}

BB11 is a major step forward, and also a foundation on which to build future improvements. This article confirms the initial plans for content of Blue Book 2011 set out in the April 2010 edition of Economic and Labour Market Review (see Everett 2010). The Pink Book will be largely unchanged from previous years. The Quarterly National Accounts consistent with Blue Book 2011 (BB11) will be a significant achievement:

- it will be the first time that the National Accounts will be published using the revised Standard Industrial Classification 2007 (SIC07), providing an expanded coverage of the service sector

- similarly, it will be the first time that the National Accounts will be published using the revised Classification of Product by Activity 2008 (CPA08)

- improved deflation methodology will be incorporated

- the National Accounts will be published using an integrated production system on a new IT platform; and

- the reference year and base year will both be 2008 , bringing them back to normal practice and completing the catching up of the lag which had opened up in earlier years

\section{Scope and contents of Blue Book 2011}

The full scope of the Quarterly National Accounts consistent with the 2011 Blue Book dataset that will be published on 5 October 2011 will be:

- an update of the current price balancing approach used in Blue book 2010 to reconcile and balance fully the three measures of GDP for 2007, 2008 and 2009. The years 1992 to 2006 will be reconciled and rebalanced using conversion factors reflecting changes to the new industrial classification - SICO7 
- the reference year will be $2008=100$

- the last base year for the chained volume measure of GDP will be 2008

- all 'industry' outputs will be classified according to the Standard Industrial Classification 2007 (SIC07)

- all 'product' outputs will be classified according to the Classification of Products by Activity 2008 (CPA08)

- Consumer Price Indexes will replace the Retail Price Indexes for the purposes of deflation (that is adjusting current price estimates of GDP onto a 'volume' basis); and

- some improvements to Financial Services statistics will be introduced

The contents of BB11 will include:

- Part 1 - Main aggregates and summary accounts

- Part 2 - Industrial analyses

- Part 3 - the sector accounts, including Non-financial corporations, Financial corporations, General government, Households and non-profit institutions serving households (NPISH) and Rest of the world

- Part 4 - other analyses and derived statistics

- Part 5 - UK Environmental Accounts

The UK Balance of Payments Pink Book for 2011 will also be released electronically on 1 November 2011.

A related development will be the production of current price Input Output Analytical (I/O) tables. These were last produced in 2006 for the year 1995. New tables, for 2005, are now being compiled and will be published in May 2011. These tables will still classify industries according to the current SIC03.

\section{System changes}

The methods used to produce past Blue Books largely reflected the independent development of systems and processes for estimating gross domestic product (GDP), short-term indicators and supply and use tables. The three stages of the GDP process, short-term indicators, quarterly GDP estimates and annual supply and use estimates, were not fully integrated into the same framework.

ONS has been working for some time on system changes to improve the quality of the National Accounts. The current development programme (Effective National Accounts and Blue Book to measure the economy - 'ENABLE') will complete, by the end of March 2011, the integration of the National Accounts production systems, and their development and migration to a new IT platform.

The IT platform, CORD, uses SAS and Oracle and has been designed by ONS for use with time series. It will provide improvements in quality control, efficiency of work processes and business resilience, as well as enabling the methods changes set out in the following sections of this article. 


\section{Methodology changes}

The annual Blue Book provides an opportunity to review methods and introduce improved methodology. In BB11, two significant changes will be introduced, a new industrial classification and an improved method of deflating current price data. There will also be some other improvements, largely in improved methods for the Financial Services. These are now described in more detail.

\section{Industrial classification}

BB11 will be published for the first time using the revised Standard Industrial Classification 2007 (SIC07) in keeping with EU regulations. These revisions are motivated by the need to adapt the classifications to changes in the structure of the economy. Some outputs have already moved to the new industrial classification, for example the Retail Sales Index has been on SIC07 since January 2010.

Key changes in SIC07 include a number of new sections giving more service sector detail. Under the new SIC, manufacturing is significantly reduced as a proportion of economic activity, which reflects the move towards more services-based economies over the past 20 years. Some of the significant changes are:

- Business activities: this broad heading was part of section $\mathrm{K}$, 'Real estate, renting and business activities', under the previous classification, but now moves to several different areas including Section M, 'Professional, scientific and technical activities'; Section N, 'Administration and support services'; Section S, 'Other service activities'; and Section J, 'Information and communication'.

- Retail sale of automotive fuel: until now, this activity has been considered part of the motor trade but in today's circumstances, the sale of fuel is better considered as part of retail activity. This is reflected by its new classification to Group 47.3 (Retail sale of automotive fuel in specialised stores).

- Recycling: the significant increase in recycling sees it move from Section D, 'Manufacturing' in SIC 2003 to Section E in SIC07, 'Water supply, sewerage, waste management and remediation activities'.

- Construction: the new wider definition of construction includes development activity.

To incorporate these changes and to provide users a time series on the new SIC07 basis, data on the previously published SIC03 basis are being converted using factors provided by the ONS's Business Register, where businesses are classified on the old and new basis. The main indicator used for these changes is turnover. This is used as a starting point for the adjustments, with some additional manual adjustments made using available additional information. This will provide a time series back to 1992 on the new SIC07 basis - the data from 2008 onwards are 'real' SIC07 data (collected using the new classification). 
ONS's Business Registers Unit has produced a cross categorisation between SIC 2003 and SIC 2007 which can be accessed via the ONS website. See Hughes (2008), Hughes and Brook (2009) and Hughes et al (2009) for details of related SIC07 articles.

\section{Deflators}

Until now, some National Accounts series have been deflated using the Retail Prices Index (RPI). BB11 will change to using to the conceptually better Consumer Prices Index (CPI) to meet best practice and in line with Eurostat's Price and Volume Handbook. The CPI is designed to be consistent with the European System of National Accounts. This should ensure greater consistency across all National Accounts compiler areas, thus improving the coherence of the National Accounts.

The basic theory and expected impact of changing from a Paasche index (used in the RPI) to a Laspeyres index (in the $\mathrm{CPI}$ ) is that it will raise the level of GDP. A separate article detailing this change and expected impact will be published prior to the publication of BB11.

\section{Financial services improvements}

BB11 will contain some improvement to financial services data. These improvements stemmed from the Better financial statistics for policy project (see Walker 2011 for the latest progress report). Generally the improvements replace existing data sources and methodology with more reliable ones but have little overall impact on top level GDP. These include adjustments for the Bank of England's Special Purpose Vehicles (SPVs), net spread earnings and debt securities.

\section{Adjustments}

The production of the National Accounts necessarily involves the application of data adjustments and balancing items, as recognised in international rules and guidance (for example SNA 2008, paragraph 22.77). There are many reasons for applying data adjustments, ranging from low level error corrections, to adjustments used to aid the alignment of high level series or balance aggregate economic series according to agreed practices.

The application of adjustments in the processes of production is not new. However, ONS has taken the opportunity, synchronised with the development and use of new systems for the production of the UK's National Accounts, to review the categorisation and application of data adjustments. The new adjustment process will be used for the first time in the production of the 2011 Blue Book and the datasets linked and associated with this product.

The new categorisation provides the benefit of clearer and more standardised recording of adjustments. The classification has also been aligned more directly with the adjustments required in the Gross National Income (GNI) process tables that the UK must provide periodically to 
Eurostat. These tables break down the data in the accounts into sources of data and types of adjustment, so the new process should simplify the production of these tables. Internal analysis and interpretation of the accounts should also be aided by the new categorisation.

There have also been changes to the stage at which some adjustments are applied, in line with the changes to production introduced with the new systems, and to resolve some current production difficulties.

\section{Other}

Some other minor revisions will be incorporated, for example where new data are available to replace buffers or estimated/forecast data. They cover, for example, areas such as child trust funds and social security administration.

\section{Revisions}

The introduction of new data and methodological changes into the National Accounts is carefully managed. Revisions for the most recent three years reflect a range of routine annual revisions, including the annual benchmarking exercise to incorporate new and revised current price data as part of the regular supply and use tables.

In Blue Book 2011, 2009 will be balanced through the input-output supply and use framework for the first time and 2007 and 2008 will be fully rebalanced. The years 1992-2006 will be revised using relevant conversion factors for the changes to the new industrial classification.

\section{Regional Accounts}

The Regional Accounts statistical bulletin 'Regional, Sub-regional and Local Gross Value Added 2010 ' is planned for release on 14 December 2011. This will include the move to the new industrial classification SIC07. The publication will reflect the SIC07 changes, and NUTS1 (Nomenclature of Units for Territorial Statistics) estimates will be for 2010 (provisional), while NUTS2 and NUTS3 estimates will be for 2009.

Estimates will be provided at NUTS1 (regional), NUTS2 (sub-regional) and NUTS3 (local area) geographical levels; with a 20- industry breakdown at NUTS1 and NUTS2. For NUTS3, a 10industry breakdown will be produced. Data will be presented for total GVA, GVA per head of population and GVA per head indices.

\section{Background}

Definitive estimates of GDP are produced at the Blue Book stage by reconciling and balancing annual estimates of expenditure, income and production in current prices through the input-output 
framework. The input-output framework consists of the regularly produced supply and use tables and input-output analytical tables. The supply and use tables are compiled around 18 months after the year in question, when comprehensive information on expenditure, income and production becomes available.

The expenditure, income and production approaches are based on different survey and administrative data sources, and each produces estimates that, like all statistical estimates, are subject to errors and omissions. Accordingly, the three measures produce different estimates, although theoretically they should be the same. A single, definitive, GDP estimate can only emerge therefore after a process of balancing and adjustment.

Supply and use tables are constructed to show a balanced and complete picture of the flows of products in the economy and illustrate relationships between producers and consumers of goods and services. In addition, they show the interdependence between industries: what industries either purchase from one another or import to produce their output.

The supply and use tables are the basis on which input output analytical tables (IOATs) are constructed. IOATs describe how different goods and services are used in the production of other goods and services. They are used to measure how changes in demand for one product can filter through to the rest of the economy.

\section{Blue Book 2011 production and risk management}

In June last year, the publication of the Quarterly National Accounts consistent with the Blue Book was delayed for several days. In the light of that experience, steps have been taken to minimise risk and ensure delivery of BB11 to time. This has taken account of advice received from Peter van de Ven, the head of National Accounts in the Netherlands, on ways of improving procedures and risk management.

These steps include:

- enhanced project management procedures

- more focus on identifying and managing key risks, including contingencies

- early planning and clear criteria for revision bids

- refreshing practical training for all the staff involved in compilation work

- extensive user testing and piloting the new ENABLE systems

- phased sign off dates

- additional progress review dates; and

- a 'twin key' quality assurance of final tables 


\section{Change to Quarterly Accounts (M2) in August 2011}

To ensure compilers have sufficient time to prepare for the major changes in Blue Book 2011, ONS has decided to change the approach to Quarterly National Accounts for Q2 2011. A Month 1 estimate, based only on output data, will be published as normal in July. Then in August, this output-based estimate will be updated. This would supplement the July Preliminary GDP estimate by replacing the third month of forecast data for the Index of Production (IoP), the Index of Services (IoS) and the monthly construction output survey with actual data. This would replace the Output, Income and Expenditure statistical bulletin in August 2011. There will be no published information on the income or expenditure components in the second quarter until the Quarterly National Accounts (QNA) release in early October.

\section{Scope of Blue Book 2012}

In line with normal practice, production of the Blue Book is being managed over a two-year period - currently BB11 and BB12. Initial plans for the scope and content of the Blue Book in 2012 include:

- $\quad$ publication date will coincide with the release of Quarterly National Accounts for Q2 2012

- reference year will be $2009=100$

- last base year for the chained volume measure of GDP will be 2009

- new methodology for the Insurance industry will be introduced (this will include revision to previous years)

- consistency between the Public Sector Finance statistics and the National Accounts will be improved, also incorporating the Whole Government Accounts (WGA), which are becoming available; and

- further improvements to Financial Services statistics will be included

\section{Future developments}

Over the next 2-3 years, ONS will make further improvements to the systems, methods and analysis supporting core National Accounts outputs.

One driver is the need to prepare for transition to the new European System of Accounts 2010, with the expected implementation date of 2014. The key changes here include the treatment as capital of Research and Development (R\&D) activities, improvements to the treatment of pension statistics, to the treatment of goods sent abroad for processing and the delineation between market and non-market activities. There will also be changes in preparation for implementation of the Balance of Payments Manual 6, to a similar timescale. ONS will consult further on the methods and data requirements for these changes, aiming to achieve compliance with international regulations at the minimum cost, while also meeting the analytic and quality needs of UK users. 
Some key additional developments are being considered for the next few years, including:

- balancing the three measures of GDP through supply and use tables in constant price (volume) terms, adding to the existing approach which involves balancing just nominal, or current price, estimates. Initially, this may be just for annual estimates, but ONS will investigate the feasibility of producing quarterly constant price supply and use tables, which would form the basis of the official estimates of GDP

- exploration of options for producing a monthly measure of GDP

- further improvements in the measurement of Financial Services

- further development of the 'satellite' accounts (including accounts for Research and Development and the Environment)

- the development of a labour accounting framework, integrated with the National Accounts

These developments will be additional to implementation of ongoing methodological improvements, which will be taken forward on a prioritised basis and subject to available resources.

ONS will also move some further areas onto CORD, offering additional benefits in terms of efficiency and quality control. Details of plans and timescales will be set out in further articles.

\section{Additional articles planned}

The following are topics of articles that are planned prior to the publication of the Blue Book. These will provide additional detail regarding methodology changes and the impact on the National Accounts:

- Deflators

- Trade in services

- Industrial classification change to SIC07

\section{Contact}

elmr@ons.gov.uk

\section{References}

Everett G (2010) 'Plans for Blue Book 2010' Economic \& Labour Market Review April 2010. Available at www.statistics.gov.uk/elmr/04_10/downloads/elmr-Apr10.pdf 
Hughes J C (2008), 'SIC 2007: implementation in ONS', Economic \& Labour Market Review August 2008. Available at www.statistics.gov.uk/cci/article.asp?id=2034

Hughes J C and Brook K (2009) 'Implementation of SIC 2007 across the Government Statistical Service (GSS)', Economic \& Labour Market Review August 2009. Available at www.statistics.gov.uk/elmr/08_09/downloads/ELMR_Aug.pdf.

Hughes J C, James G, Evans A and Prestwood D (2009) 'Implementation of Standard Industrial Classification 2007: December 2009 update, Economic \& Labour Market Review December 2009. Available at www.statistics.gov.uk/elmr/12_09/downloads/ELMR_Dec09.pdf

United Nations (2008) 'System of National Accounts 2008' (ISBN 978-92-1-161522-7)

Walker G (2011), Developing financial statistics for policy - Progress report January 2011', Economic \& Labour Market Review January 2011 Available at www.statistics.gov.uk/cci/article.asp?ID=2627 